\title{
ANALISIS MODEL PEMBELAJARAN HIPOTESIS DEDUKTIF SEBAGAI PENDIDIKAN PROGRESIF PADA PEMBELAJARAN FISIKA
}

\author{
Ayu Amelia Aprilia ${ }^{1 *}$, Nana ${ }^{2}$ \\ ${ }^{1}$ Mahasiswa Program Studi Pedidikan Fisika \\ ${ }^{2}$ Dosen Program Studi Pendidikan Fisika \\ Fakultas Keguruan dan Ilmu Pendidikan, Universitas Siliwangi \\ Tasikmalaya, Jawa Barat, Indonesia 46115 \\ Email*: aameliaaprilia@gmail.com
}

\begin{abstract}
Abstrak
Tujuan penulisan ini untuk menganalisis model pembelajaran Hipotesis-Deduktif sebagai pendidikan progresif pada pembelajaran fisika. Penulisan ini dilatar belakangi kurang tepat dan kurang bervariasinya pemilihan model pembelajaran pada kegiatan belajar di kelas khususnya pelajaran fisika. Metode yang digunakan adalah studi kepustakaan dengan mengkaji beberapa literatur untuk dianalisis kemudian dibuat kesimpulan. Model Pembelajaran Hipotesis Deduktif adalah model pembelajaran yang dalam kegiatannya dimulai dengan menggali pengetahuan umum atau pengetahuan awal siswa pada apa yang akan dipelajari. Model pembelajaran Hipotesis Deduktif berorientasi pada proses yang dapat mengembangkan keterampilan dasar siswa, khususnya keterampilan proses sains siswa. Hasil studi literatur dari beberapa referensi terpercaya, bahwa model pembelajaran Hipotesis-Dedektif termasuk dalam pendidikan bersifat progresif pada pembelajaran fisika dimana siswa mengalami dan menemukan sendiri konsep-konsep materi serta mengaitkan dalam kehidupan sosial.
\end{abstract}

Kata kunci : Model Pembelajaran Hipotesis Deduktif, pendidikan progresif, pembelajaran Fisika

\begin{abstract}
The purpose of this writing is toanalyze the hypothetical learning model as a progressive education on physics learning. This writing is based on the lack of precise and less varied selection of learning models in learning activities in the classroom, especially physics lessons. The method used is the study of literature by reviewing some literature for analysis and then drawing conclusions. The Deductive Hypothesis Learning Model is a learning model that in its activities begins by exploring the general knowledge or initial knowledge of the student on what to learn. The deductive hypothesis learning model is process-oriented that can develop students' basic skills, especially students' science process skills. The results of literature studies from several reliable references, that hypothetical learning models included in education are progressive in physics learning where students experience and discover for themselves material concepts as well as hooking in social life.
\end{abstract}

Keywords : Deductive Hypothesis Learning Model, progressive education, Physics learning 


\section{PENDAHULUAN}

Pendidikan merupakan hal yang sangat penting bagi semua manusia, khususnya generasi muda sebagai penerus bangsa. Pendidikan dalam bentuknya dibedakan menjadi dua, yaitu pendidikan formal dan non formal. Untuk pendidikan formal dilaksanakan secara teratur, terstruktur dan memiliki jenjang. Tujuan dari pendidikan formal yaitu membentuk sumber daya manusia yang baik secara jasmani maupun rohani serta menjadi manusia yang dewasa. Pendidikan formal tidak lepas dari kegiatan di sekolah dan terdapat mata pelajaran yang perlu ditempuh oleh siswa.

Dalam Pelajaran di sekolah, tidak lepas kaitannya dari pelajaran IPA (Ilmu pengetahuan alam), yaitu pelajaran yang membahas mengenai alam sekitar kita. Pada umumnya pelajaran IPA meliputi tiga bidang ilmu dasar, yaitu: biologi, fisika dan kimia. Fisika adalah ilmu yang didapat melalui langkah-langkah observasi, merumuskan masalah, membuat hipotesis, eksperimen kemudian menarik kesimpulan sehingga menghasilkan teori dan konsep. Dalam menjelaskan materi pelajaran fisika tidak cukup hanya dengan menerangkan saja, karena pada kegiatan belajarnya siswa diharuskan aktif mengikuti pelajaran. Namun pada faktanya masih banyak siswa yang menganggap pelajaran Fisika sulit. Menurut Silalahi (Nana \& Pramono, 2019) 60\% siswa beranggapan mata pelajaran fisika adalah pelajaran yang paling sulit dipahami.

Dalam hal proses pembelajaran di kelas, peran guru sangatlah penting. Guru harus pandai dalam memilih model dan cara mengajar apa yang cocok diterapkan dalam kegiatan pembelajaran supaya tujuan kegiatan pembelajaran tercapai dengan tepat dan baik. Pada pelajaran fisika guru perlu mengurangi metode pembelajaran yang bersifat Teacher Centered (berpusat pada guru) sebab siswa tidak akan mampu berkembang akhirnya siswa akan pasif dalam kegiatan belajar karena siswa hanya akan duduk dan menerima penjelasan dari guru. Salah satu model pembelajaran yang berpusat pada siswa (Student Centered) dan cocok diterapkan dalam pembelajaran Fisika adalah Model Pembelajaran Hipotesis Deduktif.

Model Pembelajaran Hipotesis Deduktif adalah model pembelajaran dimana siswa melakukan penelusuran dengan dugaan sementara dari pengetahuan awal yang dimilikinya. Menurut Dahar (1989: 164) ada tiga fase dalam model pembelajaran hipotesis deduktif, yaitu: fase eksplorasi, fase pengenalan konsep, dan fase aplikasi konsep. Selama kegiatan pembelajaran berlangsung, siswa akan menemukan sendiri dengan kegiatan eksperimen. Model pembelajaran hipotesis deduktif termasuk ke dalam model pembelajaran yang berpusat pada siswa, dimana keterlibatan siswa dalam kegiatan belajar mengajar lebih banyak dan aktif. 


\section{METODE}

Penulisan ini dilakukan menggunakan metode pendekatan kualitatif yaitu berupa data teoretis deskriptif dengan teknik studi pustaka. Data dikumpulkan untuk dianalisis kemudian disajikan dalam hasil dan pembahasan agar dapat dibawa kesimpulan. Teknik analisis data yang digunakan adalah analisis isi. Untuk menjaga ketepatan pengkajian dan mencegah kesalahan informasi dalam analisis data maka dilakukan pengecekan antar pustaka dan membaca ulang Pustaka.

\section{HASIL DAN PEMBAHASAN}

\subsection{Model Pembelajaran Hipotesis Deduktif}

Secara global, Hipotetikal / Generalitas yaitu membuat pemikiran ilmiah secara tegas dan jelas. Proses penalaran yang terletak pada mencari dan menarik kesimpulan dinamakan Generalitas. Deduktif merupakan memberikan penjelasan tentang prinsip-prinsip isi pelajaran dan kemudian menggambarkannya dalam bentuk aplikasi atau contoh dalam situasi tertentu. Penggunaan ini menjelaskan teori bentuk sebenarnya atau menjelaskan masalah umum dalam hal-hal yang bersifat khusus. Dalam kegiatan belajar menggunakan model hiposis deduktif, siswa akan memulai kegiatan belajar dengan pernyataan "sebab / apa penyebabnya?" dan dilaksanakan kegiatan eksperimen yang dibimbing oleh guru untuk membuktikan dan mencarri kebenaran hipotesis tersebut. Analisis hasil eksperimen mungkin ada beberapa hipotesis yang ditolak dan lainnya diterima hal ini merupakan fase pengenalan konsep. Sehingga akhirnya konsep-konsep yang relevan dan pola-pola penalaran yang terlibat didiskusikan dengan teman yang lain dan diterapkan pada situasi yang lain dikemudian hari

Model pembelajaran hipotesis deduktif atau biasa juga disebut Siklus belajar hipotesis deduktif adalah kegiatan pembelajaran yang dimulai dengan cara menggali pengetahuan awal siswa mengenai konsep yang akan dipelajari (Rafiuddin, 2016). Kegiatan ini dilakukan dengan cara memberikan pertanyaan yang dapat membuat siswa menentukan dan mengemukakan hipotesis berdasarkan pengetahuan awal yang mereka miliki lalu dijadikan dasar dalam mengembangkan tahap pengenalan konsep dan aplikasi konsep sesuai dengan apa yang akan dipelajari. Siklus belajar dari model pembelajaran Hipotesis Deduktif ini adalah menghendaki penalaran tingkat tinggi yang diharapkan dapat meningkatkan keterampilan proses sains siswa pada berbagai aspek seperti : mengamati, mengelompokkan, menafsirkan, membuat dugaan, melakukan percobaan, menarik kesimpulan, menerapkan konsep serta berkomunikasi. 
Selanjutnya, menurut Taufiq (dalam Asty Suryanty 2014) model pembelajaran hipotetik deduktif memiliki beberapa keunggulan, yaitu: siswa dapat dilibatkan langsung dalam hal mencari pengetahuan sendiri dengan bekal pengetahuan awal yang dimilikinya, siswa lebih aktif dalam kegiatan belajar, siswa aktif dalam melakukan pengamatan, meningkatkan minat siswa dalam belajar, serta memotivasi siswa untuk meningkatkan rasa ingin tahu tentang konsep tersebut. Model pembelajaran hipotesis deduktif menganut konstruktivisme dan termasuk ke dalam salah satu dari jenis siklus belajar yang dikemukakan oleh Lawson (Dahar, 1989: 164).

Adapun langkah-langkah dalam kegiatan belajar mengajar menggunakan model embelajaran Hipotesis Deduktif (Dahar, 1989):

Tabel 1. Langkah-langkah model pembelajaran Hipotesis deduktif

\begin{tabular}{|c|c|}
\hline Fase & Kegiatan \\
\hline Fase Ekplorasi & $\begin{array}{l}\text { Aksi-Reaksi, biarkan mereka menyuarakan } \\
\text { aspirasi terhadap materi pembelajaran, } \\
\text { setelah materi ini diperkenalkan, siswa dapat } \\
\text { membuat analisis dari apa yang disebutkan } \\
\text { tadi dan lain-lain }\end{array}$ \\
\hline \multirow{2}{*}{ Fase Pengenalan Konsep } & $\begin{array}{l}\text { Tampilkan konsep-konsep yang tepat untuk } \\
\text { mempelajari materi tersebut }\end{array}$ \\
\hline & $\begin{array}{l}\text { Buat konsep-konsep sederhana yang dapat } \\
\text { dipahami dan jelas }\end{array}$ \\
\hline \multirow{3}{*}{ Fase Aplikasi Konsep } & $\begin{array}{l}\text { Berikan waktu untuk menggunakan konsep- } \\
\text { konsep yang telah dipelajari tersebut untuk } \\
\text { menjawab pertanyaan/ tujuan pembelajaran } \\
\text { yang telah disampaikan oleh guru }\end{array}$ \\
\hline & $\begin{array}{l}\text { Siswa melakukan eksperimen dibimbing } \\
\text { oleh guru }\end{array}$ \\
\hline & $\begin{array}{l}\text { Setelah melakukan eksperimen dan menarik } \\
\text { kesimpulan, berikan tes pada siswa untuk } \\
\text { menguji sejauh mana siswa paham dan untuk } \\
\text { mengukur keberhasilan dari tujuan } \\
\text { pembelajaran tersebut }\end{array}$ \\
\hline
\end{tabular}

Kelebihan lain dari berbagai sumber lain, siklus belajar hipotesis deduktif (Wasonowati, 2014): 
1. Dapat memberikan peluang kepada siswa agar dapat membangun pengetahuan sendiri

2. Siswa dapat beraktifitas sendiri seperti ilmuwan, membentuk dan mengembangkan konsep serta keterampilan berpikir pada siswa

3. Model pembelajaran Hipotesis Deduktif dapat menghindarkan siswa dari cara belajar yang lama yaitu dengan cara menghafal

4. Pembelajaran berpusat pada siswa. Oleh karena itu, siklus belajar hipotesis deduktif sesuai dengan pelaksanaan pembelajaran kurikulum 2013 yang berfokus pada kegiatan aktif siswa (Wasonowati, 2014).

\subsection{Pendidikan Progresif}

Menurut Syamsul (2016) John Dewey merupakan tokoh yang dianggap sangat berperan dalam munculnya progresivisme. Pemikiran progresivisme didunia pendidikan merupakan respon atas model pendidikan yang otoriter dimana pendidikan hanya sebatas untuk menghapal dan memahami materi pelajaran yang disampaikan guru di kelas atau berdasarkan pada bukubuku pelajaran saja. Konsep berdasarkan kepercayaan dan pengetahuan dari progresivisme adalah setiap manusia memiliki kemampuan sendiri serta potensi dalam menghadapi masalah yang timbul dimana masalah tersbut dapat mengancam keberadaan seseorang. Selain itu pendidikan progresif atau progresivisme memandang bahwa kegiatan pembelajaran yang bersifat otoriter tidak perlu dikembangkan karena dianggap kurang memberi kebebasan dan menghargai kemampuan yang dimiliki siswa.

Pendidikan progresif didasarkan pada progresivisme dan percaya bahwa pendidikan harus didasarkan pada sifat orang untuk menjadi yang terbaik secara sosial pada orang lain dan dalam situasi kehidupan nyata. Pembelajaran ini, mengikuti prosedur yang sama seperti model pembelajaran John Dewey, percaya bahwa anak-anak belajar dengan cara yang sama seperti yang dilakukan para ilmuwan, yaitu : 1)Siswa dihadapkan pada masalah, 2)merumuskan masalah, 3)Mengusulkan hipotesis untuk mencari solusi, 4)Mengevaluasi hasil hipotesis berdasarkan pengalaman, 5)Melakukan percobaan untuk menemukan solusinya sebanyak mungkin. Dengan pemikiran ini, guru diharapkan untuk menyajikan pengalaman dan kegiatan langsung yang tidak hanya berfokus pada membaca dan menghafal, tetapi juga pada kehidupan siswanya sehingga siswa lebih bebas dalam menemukan konsep pembelajaran dan berinovasi sendiri.

prinsip-prinsip mendasar dari sekolah progresif (Syamsul, 2016) : 
1. Siswa diposisikan sebagai subjek aktif di kelas, bukan sebagai subjek pasif. Artinya sejak siswa lahir mereka sudah memiliki bakatnya sendiri termasuk akalnya, maka guru perlu memperhatikan potensi yang ada pada diri siswa tersebut.

2. Guru sebagai fasilitator dalam kegiatan belajar mengajar. Artinya guru sebagai pembimbing, yang memberikan falisitas bagi siswa pada kegiatan belajar dan guru haruslah siap dalam menyiapkan metode atau kebijakan rencana belajar sesuai dengan perkembangan zaman

3. Kegiatan belajar berpusat pada siswa (Student centered)

4. Tujuan utama dari pendidikan progresif yaitu memecahkan masalah. Pada kegiatannya yang menjadi dasar utamanya adalah bagaimana siswa diarahkan untuk dapat memecahkan masalah untuk menemukan konsep atau prinsip-prinsip

5. Sekolah sebagai miniatur dalam bermasyarakat dan pembelajaran harus kooperattif serta demokratis. Pada hal ini siswa akan dibimbing untuk belajar menyelami kehidupan diluar sekolah berdasarkan pada pengalamannya.

\subsection{Pembelajaran Fisika}

Pembelajaran merupakan proses komunikasi dua arah, baik guru dengan siswa atau antara siswa dengan siswa lainnya. Menurut Dimyanti dan Mudjiono (Sagala,2010) pembelajaran merupakan kegiatan guru secara terstruktur, agar siswa belajar secara aktif pada saat kegiatan belajar dan menekankan penyediaan sumber belajar. Menurut Gerthsen (Jumadi, 1995) Fisika adalah teori yang menerangkan mengenani gejala alam yang paling sederhana dan menemukan hubungannya dengan kehidupan dan pemecahan masalahnya dengan mengamati sendiri gejala tersebut. Pembelajaran fisika dapat mengembangkan rasa ingin tahu siswa dari proses percobaan dan pengalaman langsung, kemudian membangun dan menemukan konsep, teori serta metodologi keilmuan. Dengan pembelajaran fisika siswa akan mampu berpikir lebih kritis dalam mencari solusi pada masalah yang ada dikehidupan sehari-hari. Menurut pemahaman ilmiah yang ada, proses memperoleh pengetahuan adalah proses dimana kontak manusia dengan alam merupakan suatu pengalaman langsung, pengalaman berulang menciptakan pengetahuan dan menemukan konsep. Pelajaran fisika bukan hanya teori yang perlu dihapal dan diterapkan pada soal saja, namun perlu mencari tahu dan berdasarkan pengalaman untuk mendapatkan konsep dan prinsip-prinsip kemudian dikaitkan pada kehidupan sosial dan penerapannya dalam kehidupan sehari-hari. 


\subsection{Analisis Model Pembelajaran Hipotesis Deduktif Sebagai Pendidikan Progresif Pada Pembelajaran Fisika}

Pada kegiatan belajar mengajar agar mencapai tujuan pembelajaran, semua komponen dalam sistem pembelajaran harus saling mendukung salah satunya penggunaan model pembelajaran yang tepat. Dalam model pembelajaran yang menganut teori kontruktivisme, proses belajar bukan hanya terletak pada teori saja namun kegiatan belajar dimana perhatian diberikan pada bagaimana seseorang membangun pengetahuan, pengalaman, struktur mental, dan keyakinan yang digunakan untuk menginterpretasikan sesuatu dan peristiwa. Saat menggunakan ini sebagai hipotesis evaluasi, evaluasi harus bersifat pribadi dan sesuai dengan konteks pembelajaran. Akibatnya, proses pembelajaran dimulai dengan pengetahuan awal siswa yang tidak seragam dan kegiatan pembelajaran mengacu pada proyek yang bebas dilakukan oleh siswa, hal ini termasuk dalam ciri dari model pembelajaran hipotesis deduktif. Siswa akan diarahkan pada kegiatan menemukan sendiri konsep-konsep yang kemudian dikontruksikan dalam kehidupan bersosial sehari-hari.

Menurut Nurfathoanah (2017) pembelajaran fisika merupakan suatu proses untuk mengembangkan kemampuan dalam memahami konsep, prinsip-prinsip serta hukum-hukum fisika sehingga dalam proses belajarnya harus memperhatikan strategi / metode pembelajaran yang efektif dan efisien. Pembelajaran fisika menekan pada proses mencari dan menemukan sendiri berdasarkan pengalaman pribadi, dari hal tersebut diperlukan model pembelajaran yang dapat memberikan kegiatan belajar yang sesuai, salah satunya model pembelajaran hipotesis deduktif dimana pembelajaran berpusat pada siswa dan guru sebagai fasilitator dan pembimbing pada kegiatan belajar, selebihnya biarkan siswa yang melakukan sendiri.

Berikut terdapat beberapa persamaan dari ciri model pembelajaran hipotesis deduktif dan pendidikan progresif :

Tabel 2. Persamaan ciri-ciri hipotesis deduktif-pendidikan progresif

\begin{tabular}{|c|c|}
\hline \multicolumn{2}{|c|}{ Ciri-ciri } \\
\hline Model Hipotesis Deduktif & Pendidikan Progresif \\
\hline Berpusat pada siswa (Student Centered) & Berpusat pada siswa (Student Centered) \\
\hline Memiliki pendekatan kontekstual & Memiliki pendekatan kontekstual \\
\hline $\begin{array}{l}\text { Siswa akan memulai kegiatan belajar dengan } \\
\text { pernyataan "sebab / apa penyebabnya?" }\end{array}$ & $\begin{array}{l}\text { Pertanyaan-pertanyaan utama yang } \\
\text { ditanyakan oleh anak-anak merupakan } \\
\text { arahan utama untuk apa yang akan mereka } \\
\text { pelajari }\end{array}$ \\
\hline
\end{tabular}




\begin{tabular}{|c|c|}
\hline $\begin{array}{l}\text { Siswa diminta untuk menarik kesimpulan } \\
\text { dan didiskusikan bersama teman lain }\end{array}$ & $\begin{array}{l}\text { Semua yang terlibat dalam kegiatan } \\
\text { pembelajaran berpartisipasi dalam proses } \\
\text { pengambilan keputusan }\end{array}$ \\
\hline
\end{tabular}

Dari tabel tersebut terdapat banyak persamaan dari keduanya, sehingga model pembelajaran hipotesis deduktif yang menganut teori kontruktivisme termasuk ke dalam pedidikan progresif yang cocok digunakan dalam pembelajaran fisika sebab kegiatan belajar fisika sangat erat kaitannya dengan proses menemukan sendiri, membutuhkan pengalaman langsung dalam mempelajari materi agar siswa mudah mengkontruksikannya dalam kehidupan sosial atau kehidupan sehari-hari.

\section{KESIMPULAN}

Dari berbagai penjelasan yang telah dipaparkan, dapat ditarik kesimpulan bahwa Model Pembelajaran Hipotesis Deduktif merupakan model pembelajaran yang dimulai dengan "sebab" dan didasari pada pengetahuan awal siswa kemudian mencari kebenarannya melalui eksperimen. Sehingga dapat dikatakan bahwa model pembelajaran Hipotesis Deduktif termasuk dalam pendidikan progresif. Ciri utama dari model pembelajaran tersebut yaitu berpusat pada siswa, siswa lebih banyak mencari, menemukan dan menganalisis materi pelajaran untuk dilakukan eksperimen kemudian ditarik kesimpulan, diakhir kegiatan pembelajaran dilakukan tes untuk menguji keberhasilan kegiatan pembelajaran siswa. Model pembelajaran Hipotesis Deduktif baik untuk diterapkan pada pembelajaran fisika, hal ini disebabkan model pembelajaran Hipotesis Deduktif termasuk pada pendidikan progresif yang dibutuhkan pada kegiatan pembelajaran fisika, sebab kegiatannya tidak hanya berfokus pada produk tetapi berfokus pada proses menemukan konsep / prinsip yang dapat meningkatkan keterampilan siswa khususnya pada pembelajaran sains dimana pembelajaran sains meliputi serangkaian proses ilmiah untuk mendapatkan fakta dan diimplementasikan pada kehidupan sosial.

\section{UCAPAN TERIMAKASIH}

Terima kasih saya ucapkan pada semua pihak yang telah membantu saya dalam menyusun kesempurnaan artikel ini menjadi lebih baik. Terima kasih juga saya ucapkan kepada dosen pengampu Mata Kuliah Inovasi Pembelajaran Fisika, bapak Nana M.Pd. yang telah membimbing saya dalam penyusunan artikel ini 


\section{REFERENSI}

Dahar,Ratna Wilis. (1989). Teori Belajar. Jakarta : Erlangga Press

Haerunnissa, N., Solfarina, \& LangitaSari, I. (2019). Pengaruh Siklus Belajar Hipotesis Deduktif pada Konsep Reaksi Redoks Terhadap Keterampilan Berpikir Kritis .Jurnal Profesi Keguruan. Vol 5(1), 31-37.

Jumadi. (1995). Pengembangan Terpadu Aspek Pengetahuan-Keterapilan-Sikap dalam Proses Belajar-Mengajar Fisika di SMA. CakrawaJa Pendidikan, (2), 15-20.

Kurniawan, Syamsul. (2016). Sekolah Progresif. At-Turats : Jurnal Pemikiran Pendidikan Islam. Vol 10 (1), 3 - 12. DOI: https://doi.org/10.24260/at-turats.v10i1.446

Lovisia, E. (2017). Penerapan Model Make A Match pada Pembelajaran Fisika Kelas X SMA Negeri 2 Kota Lubuklinggau. SPEJ (Science and Physic Education Journal), 1(1), 722. https://doi.org/https://doi.org/10.31539/spej.v1i1.58

Nana \& Pramono, H. (2019). Upaya Peningkatan Kemampuan Kognitif dan Komunikasi Ilmiah Siswa Kelas X MIA 1 SMA Negeri 1 Ciamis Menggunakan Model Pembelajaran Inquiry. Diffraction : Journal for Physics Education and Applied Physics. Vol 1 (1), 1-10. DOI: https://doi.org/10.37058/diffraction.v1i1.812

Nurfathoanah. (2017). Implementasi Metode Pembelajaran GASING (Gampang, Asyik dan Menyenangkan) Terhadap Hasil Belajar Fisika Peserta Didik Kelas X SMA Negeri 3 Polongbangkeng Utara. Jurnal Pendidikan Fisika Universitas Muhammadiyah Makassar. Vol 5 (3), 351-361. DOI: https://doi.org/10.26618/jpf.v5i3.857

Puger, I. G. N. (2015). Model Pembelajaran Deduktif-Induktif Menganut Paradigma InovatifProgresif. DAIWI WIDYA : Jurnal Pendidikan FKIP UNIPAS. Vol 2 (1).

Rafiuddin. (2016). Application Of Hypothesis Deductive Cycle Learning Model In The Matter Of Chemical Equilibrium To Improve Critical Thinking Skills Student High School. International Journal of Education and Research. Vol 4(6), 249-262.

Ramadoan, N., \& Sulisworo, D. (2018). Strategi berpikir hipotetikal deduktif dalam pengembangan keterampilan berpikir kritis pada pembelajaran fisika. Seminar Nasional Quantum \#25, 2477-1511 (7pp)

Sagala, Syaiful. (2010). Konsep dan Makna Pembelajaran. Bandung:Alfabeta

Suryanty, A. (2014). Penerapan Model Pembelajaran Siklus Belajar Hipotetik-Deduktif Untuk Meningkatkan Keterampilan Proses Sains Siswa Pada Materi Tekanan. Skripsi.

Wasonowati, R. R. (2014). Penerapan Model Problem Based Learning Pada Pembelajaran Hukum-Hukum Dasar Kimia Ditinjau Dari Aktifitas dan Hasil Belajar Siswa Kelas X IPA SMAN 2 Surakarta. Jurnal Pendidikan Kimia , 66- 75. 
Wiratna Sujarweni. (2014). Metodologi Penelitian. Yogjakarta: Pustaka Barupres. 